\title{
O Desafio da Mobilidade: Um Estudo de Caso do $M$ - learning na Prática Escolar
}

\author{
André Ricardo Theodoro Velho ${ }^{1}$, Regina Barwaldt ${ }^{1}$, Vagner Rosa ${ }^{1}$ \\ ${ }^{1}$ Centro de Ciências Computacionais - Universidade Federal do Rio Grande (FURG) \\ Av. Itália km 8 - 96.201-900 - Campus Carreiros - Rio Grande - RS - Brasil \\ \{andre.theodoro@furg.br, reginabarwaldtefurg.br, vsrosa@gmail.com
}

\begin{abstract}
In recent decades followed the significant growth of mobile devices in the daily activities of society. As contributions of this work we carried out a research assay developed in the field of mobile learning and the challenges that this presents educational paradigm. Based upon this study, we applied a workshop on a course of Initial and Continuing developed with the Learning Units methodology and evaluated by categorical analysis. We conclude that mobility helps in the development of the following categories: information search, independence, curiosity, security in the exchange of information on the Internet, use and web browsing with ethical.
\end{abstract}

Resumo. Nas últimas décadas acompanhamos o crescimento significativo dos dispositivos móveis nas atividades diárias da sociedade. Como contribuições deste trabalho realizamos um ensaio de pesquisas desenvolvidas na área da aprendizagem móvel e dos desafios que tal paradigma educacional apresenta. Embasados neste estudo, aplicamos uma oficina em um curso de Formação Inicial e Continuada, desenvolvida com a metodologia de Unidades de Aprendizagem e avaliada através da análise categorial. Concluímos que a mobilidade auxilia no desenvolvimento das seguintes categorias: busca de informação, independência, curiosidade, segurança na troca de informações na internet, utilização e navegação na internet com postura ética.

\section{Introdução}

Estamos inseridos em uma sociedade totalmente avançada cientificamente, onde os aparatos tecnológicos norteiam a vida de muitos, a cada dia fica mais evidente a interação diária entre homens e smartphones, essa evidência, fica mais clara ainda ao analisarmos o comportamento dos jovens e seus dispositivos móveis. O celular hoje é um dos meios maios utilizados para captura de acontecimentos, compartilhar informações em redes sociais, ouvir música, receber e enviar mensagens de texto, entre outros [TECHINBRAZIL, 2015].

$\mathrm{Na}$ área da educação profissional, uma vertente que tem crescido no Brasil é a de Cursos de Formação Inicial e Continuada (FIC), que são cursos de diversas áreas do conhecimento, de carga horária enxuta e que proporcionam ao discente conteúdo e prática necessários para apropriá-lo dentro de uma ou várias competências. Esses cursos possuem geralmente um cunho profissionalizante e servem como uma alavanca para o concorrido mercado de trabalho. O perfil dos discentes é formado de jovens em busca 
do primeiro emprego e adultos que necessitam de novas habilidades ou querem recolocação no mercado de trabalho.

Os cursos FIC tem se utilizado das Tecnologias da Informação e Comunicação (TIC) no âmbito educacional, percebendo que a mesma, é uma poderosa ferramenta que apoia a aprendizagem de forma eficaz e que auxilia o professor a desenvolver as competências e vivências necessárias para a apropriação de habilidades, conhecimentos e atitudes que seus planos de curo versam.

O paradigma da computação móvel tem obtido cada vez mais destaque na comunidade acadêmica, conforme, sua utilização cresce de forma acelerada. Com o aumento do uso de smartphones e novas possibilidades de negócios e comercialização a educação, também, aderiu as práticas de computação móvel. Todavia, como todo paradigma, desafios emergem em sua utilização. Na mobilidade no contexto escolar não é diferente, novos desafios de usabilidade, operacionalidade, assim como, capacidade técnica e pedagógica surgem todos os dias.

Ao vislumbrarmos este desafio do uso da aprendizagem móvel na educação profissional e ao buscarmos na literatura respostas que nos auxiliassem encontramos no m-learning uma sugestão de aprendizagem diferenciada, percebemos que esse ensino deveria ser pautado em uma metodologia de ensino construtivista para que pudéssemos qualificar essa proposta de educação em cursos FIC. Para criação de um estudo analítico sobre as problemáticas levantadas exploraremos o estudo de caso de um Projeto de Ação na Escola (PAE) para verificarmos se o uso do m-learning como uma ferramenta construtivista em cursos de formação inicial e continuada presenciais é uma solução viável para o desenvolvimento dos educandos.

\section{O Desafio do M-Learning na Educação}

Para que possamos traçar um panorama dos desafios enfrentados pela educação profissional brasileira no contexto de mobilidade, assumimos como definição de Aprendizagem Móvel ou m-learning o processo de ensino e aprendizagem que ocorre, fundamentalmente, apoiado no uso das Tecnologias de Informação e Comunicação Móvel e Sem Fio (TICSF) [OLIVER et al., 2014; GARCIA-CABOT et al., 2014]. Esta aprendizagem, pode envolver ainda, discentes que se encontram separados territorialmente ou, mesmo, fisicamente distante de outros discentes ou, até, do professor, permitindo assim, que aja uma desconstrução do que se tem como espaço físico formal de educação [KOUNINEF et al., 2012; FERNANDES, 2012].

Partindo deste ponto conseguimos observar desafios que emergem em decorrência da utilização desta forma de ensino e aprendizagem. Com este olhar aguçado nos deparamos com a realidade que a tecnologia móvel e sem fio possui, ainda, um grande déficit de eficiência em muitos locais, o que pode gerar, indisponibilidade e instabilidade para sua prática em algumas regiões.

A utilização de smartphones e de alguns outros aparelhos que auxiliam a mobilidade são de uso proibido em algumas escolas e de veto na maioria das salas de aulas. O pensamento de muitos professores que os aparatos tecnológicos atrapalharão e distrairão os aprendizes, necessita de uma profunda reflexão que traga a luz as potencialidades pedagógicas dessas ferramentas. 
Neste contexto, se deve observar as limitações que condizem ao acesso à Internet, transferência de dados e a utilização de mensagens de texto devido ao auto custo, o que pode impossibilitar o uso por parte de alguns alunos. Se a escola não ofertar uma rede de dados ou o aluno não possuir em sua casa as atividades de ensino e aprendizagem tornam-se inviáveis.

Todavia, a comunidade científica tem estudado e desenvolvido soluções que auxiliem os professores a desenvolverem atividades de ensino e aprendizagem que se utilizem do m-learning. Alguns trabalhos que pontuam soluções interessantes devem ser mencionados, como o m-tutorial uma ferramenta de autoria para desenvolvimento de tutorias elaborado e abordado por Rachid e Ishitani (2012) que possibilita a criação de objetos de aprendizagem de forma dinâmica e interativa.

Através do trabalho de Filho e Barbosa (2012) é possível se obter a definição de um conjunto de características e requisitos que os ambientes de aprendizagem móvel devem possuir. Os autores, também, apresentam uma revisão sistemática que viabiliza a compreensão do olhar da comunidade científica a este paradigma de ensino e aprendizagem.

Outro trabalho que explora o uso da ferramenta Whatsapp como um ambiente virtual de aprendizagem é apresentado pelos autores Oliveira et al. (2014). Relatam uma experiência da aplicação do m-learning em um curso a distância, enfatizando o alcance pedagógico e os pontos fracos encontrados na vivência.

No âmbito internacional os trabalhos dos autores Abachi e Muhammad (2014) destacam-se ao abordar o impacto ocasionado na prática do m-learning através do ponto de vista do aluno e do professor. Garcia-Cabot et al. (2014) trazem a luz um estudo empírico sobre a adaptação de alunos, professores e escola ao contexto da aprendizagem móvel e o impacto que a mesma tem no processo de ensino e aprendizagem nos atores envolvidos.

\section{O Desafio Computacional da Mobilidade Educacional}

Algumas questões que merecem ser abordadas quanto ao desafio da computação para, que a mesma, possibilite uma aprendizagem móvel eficiente e eficaz são as restrições provindas de cada dispositivo. Tratando-se, especificadamente, de smartphones cada empresa desenvolve o seu aparelho de acordo com métricas que variam desde poder aquisitivo do público alvo a inovações tecnológicas, o que gera, uma grande diversidade de aparelhos móveis guiados por tendências que se transformam velozmente.

O tamanho reduzido de alguns aparatos pode ocasionar algumas ressalvas quanto ao seu uso, como por exemplo: o tamanho da tela que pode ser muito pequena para a leitura de textos, entrada lenta de texto com dificuldades para digitação, poder de processamento de dados reduzido, limitação da memória do dispositivo, interfaces que não sejam user-friendly ${ }^{l}$, entre outros [KOUNINEF et al., 2012]. Se partimos do prelúdio que cada aluno usará o seu equipamento, já visualizamos a necessidade de uniformizar as atividades, ações e formas de interação que ocorrerão na aplicação da

\footnotetext{
${ }^{1}$ User-friendy, amigável em português, é uma expressão usada por Jacob Nielsen para definições de usabilidade.
} 
aprendizagem móvel. Neste caso, para que haja uma saída eficiente para a limitação de memória e processamento dos smartphones, se pode recorrer ao uso do cloud computing $^{2}$, como forma de desenvolver arquiteturas para a prática de m-learning, entendendo que, através desta tecnologia é possível o acesso a recursos diversos sem acarretar sobrecarga de processamento e armazenamento de dados ao aparelho do aprendiz.

O autor Molnar et al. (2012) discorre a respeito das dificuldades enfrentadas na generalização da aprendizagem móvel, ressaltando, os desafios da infraestrutura de acesso à internet, especialmente, nas redes sem fio. $\mathrm{O}$ auto custo da transferência de dados, sobretudo, quando conteúdos multimídia são transferidos pode ser um inviabilizador da expansão do m-learning. $\mathrm{O}$ autor, também sugere, algumas soluções que podem minimizar o problema levantado, neste caso, ele relata uma proposta de entrega de conteúdo educacional de forma contextualizada, realizando dessa forma, a transferência de conteúdos com dois tipos de definição e qualidade de imagem, o que por consequente, permite que o aprendiz escolha custos e tamanhos do conteúdo a ser estudado.

Contudo, o autor ainda discute, as possibilidades de crescimento do m-learning usando a perspectiva de que os aparatos tecnológicos móveis, especificadamente os smartphones, são vastamente comercializados tanto em países emergentes quanto em países desenvolvidos. Neste ponto, este tipo de tecnologia se difere do restante das TIC, que em alguns países mais pobres não são facilmente adquiridas. Outro fator, que o autor utiliza para contextualizar as possibilidades computacionais da aprendizagem móvel, é a expansão e crescimento dos serviços de telefonia móvel em países menos desenvolvidos.

Uma solução que vem sendo adotada e estudada pela academia, como forma de superação aos desafios de diferentes projetos de aprendizagem móvel, é a integração de dispositivos móveis com as plataformas já existentes e funcionais de e-learning. Desta forma, se obtêm um maior alcance do m-learning, tendo em vista, que muitas instituições já se utilizam de plataformas de e-learning, como por exemplo, a plataforma Moodle, uma das mais difundidas e utilizadas no Brasil.

\section{Estudo de Caso: M-learning na prática escolar}

Como um caso de estudo do m-learning na prática escolar, desenvolvemos um PAE onde pudéssemos verificar, a supracitada, como uma ferramenta construtivista em cursos FIC presenciais e relacionar o desafio da mobilidade neste contexto. Acredita-se que o mobile learning torna-se uma ferramenta eficaz quando atrelada há uma metodologia de ensino que enfoque e potencialize seus recursos diversos. Tal afirmativa revela uma necessidade de aprendizagem personalizada, ou seja, uma aprendizagem que reconheça a diversidade, as diferenças e a individualidade na forma como o ensino é desenvolvido, conferido e amparado [TRAXLER, 2009].

\footnotetext{
${ }^{2}$ Cloud computing ou computação em nuvem é a capacidade de computação infinitamente disponível e flexível. A nuvem é tudo aquilo que fica por detrás da conexão.
} 
Baseado no construtivismo do conhecimento, Piaget (1975), aborda a concepção do "aprender a aprender", que permite que se crie as possibilidades de os alunos buscarem suas informações e conhecimentos que os farão apropriarem os conteúdos trabalhados, dessa forma começamos a gerar alunos mais autônomos, que conseguem por si ampliarem suas concepções e entendimentos. Tal pensamento nos remete a compreensão que o discente desenvolve o saber de uma forma mais assertiva na construção do conhecimento que foi desenvolvido.

A teoria construtivista entende que a construção do conhecimento se faz na inteiração do sujeito com o mundo, com os objetos que lhes são disponibilizados, fazendo com que conceitos, tais como, o da aprendizagem baseada em memorização não seja eficaz para a construção de um conhecimento com estruturas cognitivas sólidas nos discentes, sendo que elas não foram estabelecidas pelo próprio aluno, conforme as suas próprias concepções, e sim impostas através de um método onde o aluno decora o conhecimento e não se apropria do mesmo. Dessa forma, a teoria nos traz a luz de que o conhecimento não nos é dado, não está pronto ou acabado e em nenhum momento é como algo terminado, ele irá se constituir pelas inteirações que o indivíduo irá ter com o meio físico e social, com o simbolismo humano, com o mundo das relações sociais em que o sujeito está incluso. A aprendizagem se fará na força de suas ações e percepções com a miscigenação dos meios ao qual o aprendiz está exposto no momento de sua aprendizagem [BECKER, 2012].

As Unidades de Aprendizagem (UA) apresentam-se como um modo alternativo do planejamento, elaboração e organização dos trabalhos em sala de aula [GALIAZZI et $a l, 2004]$, tal percepção, une-se de modo eficaz com a proposta do m-learning, se ainda, levarmos em consideração que as unidades de aprendizagem são alicerçadas no diálogo, no trabalho em equipe, no planejamento e na pesquisa [MORAES et al, 2007].

Desta forma, fora desenvolvido um PAE que promovesse o ambiente necessário para a utilização das UA, utilizando à vista disso, os aparatos tecnológicos móveis, como um meio de encantamento dos alunos durante o processo de ensino e aprendizagem. Acreditando, que através dessa prática obteríamos resultados aquém dos já obtidos em turmas anteriores. A oficina foi aplicada em uma instituição prestigiada na área de ensino profissionalizante e que oferta cursos FIC. As atividades ocorreram em uma turma do curso de Informática Fundamental de forma interdisciplinar, perfazendo, diferentes conhecimentos e habilidades requeridas dos discentes.

O curso de Informática Fundamental consiste de seis componentes de aprendizagem que são: Sistema Operacional: Windows, Editor de Textos: Microsoft Word, Editor de Planilhas: Microsoft Excel, Internet e Redes Sociais, Editor de Apresentação: Microsoft PowerPoint e HTML. O plano de curso versa que o discente apropriado desses conhecimentos tem as competências fundamentais da informática para utilizá-la como uma ferramenta de apoio para as mais diversas atividades. O PAE foi realizado em um momento do curso em que os alunos estavam finalizando o componente de Excel e iniciando o componente de PowerPoint até o seu término e início do componente de HTML, perfazendo o período de quinze dias. 
V Congresso Brasileiro de Informática na Educação (CBIE 2016)

Anais do XXII Workshop de Informática na Escola (WIE 2016)

\subsection{Aplicação do Projeto de Ação na Escola}

A oficina teve quatro etapas divididas em três horas e vinte minutos aula por dia, totalizando quinze dias corridos para sua execução. Sua aplicação se deu conforme a Tabela 1.

Tabela 1. Cronograma da Aplicação do PAE

\begin{tabular}{|c|c|c|}
\hline Aula & Gênero(s) Adotado(s) & Objetivos / Observações \\
\hline $\begin{array}{l}1^{\circ} \quad \text { Etapa } \\
\text { Presencial }\end{array}$ & $\begin{array}{l}\checkmark \text { Metodologia } \\
\text { Construtivista } \\
\text { Unidades de } \\
\text { Aprendizagem (UA). }\end{array}$ & $\begin{array}{l}\checkmark \text { Explanação da proposta de aprendizagem com utilização dos } \\
\text { aparelhos móveis, explanação dos objetivos das atividades de } \\
\text { Aprendizagem que seriam realizadas, acesso e instalação do } \\
\text { software de comunicação e delimitações das regras de uso. }\end{array}$ \\
\hline $\begin{array}{l}2^{\circ} \quad \text { Etapa } \\
\text { Presencial }\end{array}$ & $\begin{array}{l}\checkmark \text { Problemática. } \\
\checkmark \quad \text { Tópicos de } \\
\text { discussões mediado. }\end{array}$ & $\begin{array}{l}\checkmark \text { Brainstorm das temáticas que elucidavam o PAE, Criação do } \\
\text { grupo da turma para realização das atividades no software de } \\
\text { comunicação, }\end{array}$ \\
\hline $\begin{array}{lr}3^{\circ} \quad \text { Etapa } & - \\
\text { Presencial com } & \text { cossibilidades } \\
\text { pose } \\
\text { atividades a } \\
\text { distância devido } \\
\text { a mobilidade }\end{array}$ & $\begin{array}{l}\checkmark \quad \text { Tópicos de } \\
\text { discussões mediado. } \\
\checkmark \quad \text { Início das } \\
\text { Atividades. } \\
\checkmark \quad \text { Possibilidade de } \\
\text { realizar atividades } \\
\text { extraclasse. } \\
\checkmark \quad \text { Exercícios de } \\
\text { fixação. }\end{array}$ & $\begin{array}{l}\checkmark \text { Início das atividades de aprendizagem móvel, material de } \\
\text { apoio disponibilizado através do grupo no software de } \\
\text { comunicação, neste momento foi aberto a possibilidade dos } \\
\text { alunos saírem do laboratório de informática se espalharem pela } \\
\text { escola para realizar as tarefas pontuadas com a mobilidade } \\
\text { escolar, disponibilização de material para atividades extraclasse } \\
\text { que auxiliassem a aprendizagem, compartilhamento de links, } \\
\text { vídeos e textos que auxiliavam os alunos em novas descobertas, } \\
\text { momentos de exercícios de fixação onde os alunos retornavam } \\
\text { para a sala de aula e desenvolviam materiais com os } \\
\text { conhecimentos alavancados. }\end{array}$ \\
\hline $\begin{array}{l}4^{\circ} \quad \text { Etapa } \\
\text { Presencial }\end{array}$ & $\begin{array}{l}\checkmark \quad \text { Tópicos de } \\
\text { discussões mediado. } \\
\checkmark \quad \text { Finalização das } \\
\text { Atividades. } \\
\checkmark \quad \text { Exposição dos } \\
\text { trabalhos. }\end{array}$ & $\begin{array}{l}\checkmark \text { Continuidade das atividades de aprendizagem e } \\
\text { desenvolvimento de trabalhos mais complexos. A mobilidade foi } \\
\text { empregada, novamente, na possibilidade de os jovens } \\
\text { trabalharem novamente espalhados pela escola desenvolvendo } \\
\text { atividades distintas, professor mediando todas as ações, auxílio } \\
\text { técnico do professor, finalização dos trabalhos desenvolvidos, } \\
\text { exposição de todos os trabalhos. }\end{array}$ \\
\hline
\end{tabular}

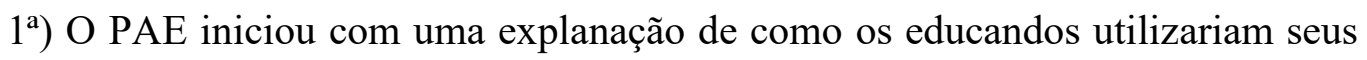
smartphones para realizarem as atividades propostas, contemplando as suas regras, os seus objetivos, assim como, um software de comunicação ${ }^{3}$ foi instalado nos smartphones que não o possuíam.

$\left.2^{a}\right)$ Um grupo de conversas foi criado para turma no software de comunicação. Neste momento, também, criou-se um primeiro brainstorm para contextualização sobre mobilidade, smartphones, uso de redes sociais na educação e temas que inserissem os educandos nas atividades que ocorreriam durante o PAE.

$3^{\text {a) }}$ A atividade foi iniciada, respeitando pausas estratégicas onde todos realizaram exercícios complementares de fixação.

$4^{\text {a) }}$ O professor agindo como mediador das descobertas realizadas, das discussões levantadas e dos momentos de ajuda técnica.

As atividades realizadas consistiam em permitir que os alunos utilizassem de seus dispositivos móveis para ler, criar, desenvolver e manipular as informações e

\footnotetext{
${ }^{3} \mathrm{O}$ software de comunicação escolhido para o caso de estudo foi o WhatsApp.
} 
materiais que o docente disponibilizava no grupo de comunicação, para que, então, os discentes contextualizassem, os mesmos, em suas atividades. Dessa forma, os alunos divididos em grupos puderam se dirigir para algum ambiente da escola que gostassem, como pátio, biblioteca, refeitório ou jardim de inverno, pois a ideia, também era tirá-los do laboratório de informática para que entendessem que poderiam aprender informática de qualquer ambiente escolhido.

Posicionados dispersos na escola o docente lançava desafios no software de comunicação e determinava um tempo para que eles enviassem suas resoluções dos desafios, pontuando a agilidade na entrega e a qualidade da resolução. Dúvidas poderiam ser sanadas através do grupo no aplicativo dos smartphones, para que todos os alunos obtivessem as mesmas explanações as explicações eram feitas por vídeos gravados pelo docente em sala de aula e compartilhados pela ferramenta. Em determinados momentos os alunos deveriam tirar selfies de seus grupos $\mathrm{e}$ compartilharem no aplicativo pontuando a participação de seus grupos. Durante a realização das atividades o docente visitava os grupos auxiliando-os nas suas dificuldades técnicas, registrando o auxílio, por vídeo, foto ou áudio e compartilhando no grupo para que os demais alunos participassem de todos os momentos.

\subsection{Metodologia}

As formas de avaliação das atividades se deram de três maneiras distintas. A primeira, uma avaliação do discente sobre as atividades de m-learning, através de uma entrevista. A segunda avaliação foi realizada pelo docente na prática em sala de aula, onde, a qualificação se deu na observação do docente quanto as atitudes e ações dos discentes nas práticas das propostas das atividades. $O$ saber fazer a partir do conhecimento construído de forma móvel conduziu a avaliação individual dos alunos. E por fim, a terceira avaliação se deu na exposição dos trabalhos desenvolvidos.

Os educandos foram convidados a responder apenas duas questões, através de uma entrevista qualitativa, onde os alunos necessitavam responder perguntas de forma dissertativa que, acreditamos, sintetizariam a experiência vivida pelos mesmos, fomentando a fala dos alunos e contextualizando a vivência da mobilidade na sala de aula. Segundo Bogdan \& Biklen (2010), "uma entrevista é utilizada para recolher dados descritivos na linguagem do próprio sujeito, permitindo ao investigador desenvolver intuitivamente uma ideia sobre a maneira como os sujeitos interpretam aspectos do mundo", sendo assim, obtemos a visão dos alunos da prática do m-learning na construção de conhecimento. As perguntas que os discentes responderam eram:

$1^{\circ} \mathrm{O}$ que você achou da experiência de utilizar seu smartphone como um objeto de aprendizagem? Explique.

$2^{\circ}$ Você acredita que essa experiência interferiu positivamente na sua aprendizagem? Explique.

Para o exame dos resultados encontramos na análise categorial [BARDIN, 1977] uma forma de desmembrar os dados qualitativos. Interpretamos, dessa forma, os resultados alcançados com o caso de estudo, agrupando em categorias, a análise dos textos gerados pelos alunos, através, da entrevista respondida. 
V Congresso Brasileiro de Informática na Educação (CBIE 2016)

Anais do XXII Workshop de Informática na Escola (WIE 2016)

\section{Discussão e Análise dos Resultados}

As entrevistas foram analisadas e elencaram categorias que contextualizam a vivência dos alunos, os saberes, as atitudes e opiniões, dos mesmos, quanto as práticas realizadas na oficina do PAE. Vale salientar que, os estudantes do curso de Informática Fundamental, onde as atividades ocorreram, possuem uma faixa etária entre quatorze e dezessete anos, escolaridade homogêneas e são de diferentes etnias. O número total de alunos que participaram desta oficina é doze.

Tabela 2. Categorias

\begin{tabular}{|c|c|}
\hline Categorias & Conceitos Norteadores \\
\hline $\begin{array}{l}\text { Busca } \\
\text { Informação }\end{array}$ & $\begin{array}{l}\text { Os alunos discorreram sobre diferentes formas e meios que utilizaram para buscar a } \\
\text { informação, evidenciando, a prática do m-learning como propulsor de novas descobertas. } \\
\text { Além disso, os relatos, salientam que os discentes já utilizam a ferramenta para busca de } \\
\text { informações que lhe apreciam, todavia, não tinham como prática no contexto escolar. }\end{array}$ \\
\hline Independência & $\begin{array}{l}\text { Percepção dos alunos do desvinculo de necessitarem de terceiros para protagonizarem sua } \\
\text { aprendizagem e identificação de ferramentas (meios) que o tornam independentes no } \\
\text { desenvolvimento de conhecimentos, habilidades e competências; }\end{array}$ \\
\hline Curiosidade & $\begin{array}{l}\text { Percepção dos alunos de que o uso da curiosidade, aliado, a prática da pesquisa, da busca } \\
\text { de informação e da contextualização de seus entendimentos gera novos conhecimentos, } \\
\text { habilidades e competências. }\end{array}$ \\
\hline $\begin{array}{l}\text { Segurança na troca } \\
\text { de informações na } \\
\text { internet }\end{array}$ & $\begin{array}{l}\text { Os alunos discorreram sobre a importância da segurança, no contexto de troca de } \\
\text { informações na internet, em suas práticas diárias na Web. Relatos de problemas } \\
\text { ocasionados pela falta de segurança, assim como, meios de proteção embasaram o discurso } \\
\text { dos alunos. }\end{array}$ \\
\hline $\begin{array}{lr}\text { Utilização } & \text { e } \\
\text { navegação } & \text { na } \\
\text { internet } & \text { com } \\
\text { postura ética } & \end{array}$ & $\begin{array}{l}\text { Percepção dos alunos quanto a importância de se utilizar a internet não apenas como um } \\
\text { meio de entretenimento, mas sim, como uma ferramenta de trabalho que, exige dos } \\
\text { mesmos, postura ética, concentração, organização e persistência. }\end{array}$ \\
\hline
\end{tabular}

As categorias elencadas evidenciam a necessidade de uma aprendizagem personalizada [TRAXLER, 2009], permitindo então, que vejamos o m-learning como uma metodologia de ensino e aprendizagem que propicia o protagonismo do aluno. As categorias, permitem também, a ratificação da importância do "aprender a aprender" [PIAGET, 1975], que se torna notório nas categorias: Busca de Informação, Independência e Curiosidade. As supracitadas, também, foram provadas pela união da prática do mobile learning e das Unidades de Aprendizagem, estas, propiciaram o cenário necessário para a interação dos indivíduos com o meio físico, tecnológico e social [BECKER, 2012].

As categorias Segurança na troca de informações na internet e Utilização e navegação na internet com postura ética, por sua vez, evidenciam os desafios encontrados na mobilidade no contexto escolar [OLIVER et al., 2014; GARCIACABOT et al., 2014]. As dificuldades de adaptação dos alunos ao contexto de aprendizagem móvel, as distrações que o uso do software de comunicação pode gerar e a preocupação na insegurança, percebida por alguns, na troca de informações através de seus dispositivos móveis, podem ser, dificuldades que o docente vá enfrentar em suas ações de ensino e aprendizagem móvel.

Não categorizado pelos alunos, porém, percebido pelo docente na aplicação do PAE, está a infraestrutura precária de rede sem fio e a dificuldade de algumas ações, devido a mesma. Vídeos, imagens e áudios que demoravam a carregar ou não 
V Congresso Brasileiro de Informática na Educação (CBIE 2016)

Anais do XXII Workshop de Informática na Escola (WIE 2016)

carregavam, internet instável e a impossibilidade de acesso fora da escola, por parte de alguns discentes, dificultaram e muitas vezes inviabilizaram alguma ação na prática do m-learning.

\section{Considerações Finais}

Através da investigação do desafio da mobilidade no contexto escolar, descrevemos a conjuntura, do cenário brasileiro e internacional da prática do m-learning. Através de tal embasamento, pudemos desenvolver um projeto de ação na escola que investigasse o uso, do supracitado, no contexto de cursos de Formação Inicial e Continuada. Para analisarmos o caso de estudo, nos utilizamos, da análise categorial dos discursos realizados pelos alunos que participaram do PAE.

Das categorias elencadas, através das entrevistas dos alunos, pode-se obter um viés, baseado no aluno, da prática de ensino e aprendizagem de mobile learning. Desta forma, as categorias descrevem os pensamentos, saberes, valores e atitudes que os alunos desenvolveram ao longo do desenvolvimento do PAE. As categorias, também, podem auxiliar o docente na análise crítica da possibilidade de adaptar este método de ensino e aprendizagem em sua prática em sala de aula. Além de, expor as dificuldades e dilemas que a mesma pode vir a proporcionar.

Todavia, a simples utilização do m-learning na prática docente não garante maior ganho nas atividades de ensino e aprendizagem. Existe a necessidade de alinharse, juntamente com a aprendizagem móvel, metodologias de ensino que contextualizem a utilização das mesmas e que proporcionem uma vivência do conteúdo estudado pelo aluno. Em um contexto onde as tecnologias se renovam todos os dias, e onde, a informação está ao alcance de todos, surge um cenário onde o docente necessita reinventar-se e adaptar-se a novos paradigmas, para que consiga, alcançar todos os seus educandos.

Dos desafios da mobilidade em cursos FIC percebemos que um vasto caminho ainda deve ser percorrido. A utilização de m-learning deve ser pensada e repensada a todo momento, considerando sempre, as limitações computacionais, assim como, as habilidades e competências necessárias do docente e discente para que aja sucesso na aplicação. E por fim, verificamos que o m-learning, neste contexto, se tornou uma ferramenta aceitável e construtivista no desenvolvimento das atividades de ensino e aprendizagem do estudo de caso.

\section{Referencias}

ABACHI, H. R., \& MUHAMMAD, G. (2014). The impact of m-learning technology on students and educators. Computers in Humam Behavior, 30,491-496, doi:10.1016/j.chb.2013.06.018.

BARDIN, Laurence. Análise de conteúdo. Lisboa: Edições 70, 1977.

BECKER, F. Educação e construção do conhecimento. 2. ed. Porto Alegre: Penso, 2012.

BOGDAN, R. \& BIKLEN, S. (2010). Investigação Qualitativa em Educação: Uma Introdução à Teoria e aos Métodos. Porto: Porto Editora. 
V Congresso Brasileiro de Informática na Educação (CBIE 2016)

Anais do XXII Workshop de Informática na Escola (WIE 2016)

FERNANDES K.T; e-Learning via dispositivos móveis no Brasil: Estado da Arte e Desafios à Luz do Acesso Participativo e Universal do Cidadão Brasileiro ao Conhecimento; 2012. Disponível em <http://www.lbd.dcc.ufmg.br /colecoes/desafie!/2012/0019.pdf>. Acesso em: abr. 2016.

FILHO, N. F. D. BARBOSA, E. F.; Estudo e Definição de um Conjunto de Características e Requisitos para Ambientes de Aprendizagem Móvel, Simpósio Brasileiro de Informática na Educação. SBIE . ISSN 2316-6533O, 26-30. 2012.

GALIAZZI, M. C.; GARCIA, F. Á.; LINDEMANN, R. H. Construindo Caleidoscópios - organizando unidades de aprendizagem. In: MORAES, R.; MANCUSO, R. Educação em Ciências - produção de currículos e formação de professores. Ijuí: Unijuí, 2004. p. 65-84.

GARCÍA-CABOT, A., de-MARCOS, L., \& GARCÍALOPEZ, E. (2014). An empirical study on m-learning adaptation: learning performance and learning contexts. Computers \& Education.

KOUNINEF, B. et al. Lms inttic system using mobile technology and podcasting in blended learning. In: Education and eLearning Innovations (ICEELI), 2012 International Conference on. [S.1.: s.n.], 2012. p. 1-6.

MOLNAR, A.; MUNTEAN, C. Mobile learning: An economic approach. In: Intelligent and Adaptive Learning Systems Technology Enhanced Support for Learners and Teachers. [S.1.: s.n.], 2012. p. 311-326.

MORAES, R.; GOMES, V. Uma Unidade de Aprendizagem sobre Unidades de Aprendizagem. In: GALIAZZI, M. C. (Org.). Construção curricular em rede na educação em ciências: uma aposta de pesquisa na sala de aula. Ijuí: Unijuí, 2007. p. 243-280.

OLIVEIRA, Estêvão Domingos Soares de; ANJOS, Eudisley Gomes dos; OLIVEIRA, Felipe Soares de; SOUSA, Hercilio de Medeiros; LEITE, Jan Edson Rodrigues. Estratégias de uso do WhatsApp como um ambiente virtual de aprendizagem em um Curso de Formação de Professores e Tutores. In Simpósio Internacional de Educação a Distância. São Carlos: Universidade Federal de São Carlos. 2014.

PIAGET, J. Problemas da psicologia genética. Os pensadores. São Paulo: Abril Cultural, 1975.

RACHID, L. C., ISHITANI, L. (2012). m-tutorial: ferramenta de autoria para desenvolvimento de tutoriais voltados para o m-learning. In: Revista Brasileira de Informática na Educação (RBIE), v.20, n.1.

TECHINBRAZIL. (2015) "Uso de Smartphones no Brasil", In: $<$ https://techinbrazil.com.br/uso-de-smartphones-no-brasil>. Acesso em: set. 2015.

TRAXLER, J. Current state of mobile learning. In: ALLY, M (Org.). Mobile learning: transforming the delivery of education and training. Edmonton: AU Press, Athabasca University, 2009. Disponível em: www.aupress.ca/index.php/books/120155. Acesso em: set. 2015. 